\title{
Orientation of lutein in a lipid bilayer - revisited*
}

\author{
Marta Pasenkiewicz-Gierula ${ }^{凶}$, Krzysztof Baczyński, Krzysztof Murzyn and Michał Markiewicz \\ Department of Computational Biophysics and Bioinformatics, Faculty of Biochemistry, Biophysics and Biotechnology, Jagiellonian University, \\ Kraków, Poland
}

\begin{abstract}
Lutein is present in the human retina and lens, where it plays a protective role. As lutein is associated with the lipid matrix of biomembranes, the role depends on its membrane location. Experimental studies predicted two orientations of lutein in a phosphatidylcholine (PC) bilayer: vertical and horizontal. Using a molecular dynamics simulation, we observed, in two different PC bilayers, both orientations of lutein, and in each bilayer, a single change from vertical to horizontal orientation or vice versa. Both orientations were stabilized by hydrogen bonding of lutein $\mathrm{OH}$ groups with mainly carbonyl but also phosphate oxygen atoms of PC.
\end{abstract}

Key words: molecular modeling, macular pigment, tilt angle

Received: 17 October, 2011, accepted: 01 March, 2012; available on-line: 17 March, 2012

\section{INTRODUCTION}

Lutein is a xanthophyll found in many fruits and vegetables. It is also, together with zeaxanthin, the most common ocular pigment in humans. In the retina, its highest concentration is in the fovea, the central region of the macula lutea (yellow spot) but the concentration rapidly decreases with an increasing distance from the fovea (Hammond et al., 1997). Lutein is also present in the human lens, and in a higher concentration in epithelial and cortical cell layers than in the nucleus (Bernstein et al., 2001).

In the retina, lutein as well as other macular pigments, protect against excess blue light. It has been estimated that the pigments are able to reduce the blue light intensity by 40\% (Snodderly et al., 1984). Moreover, lutein can also act as an antioxidant by reducing the rate of photooxidation (Khachik et al., 1997).

In humans, lutein originates exclusively in the diet (Khachik et al., 1997). It has been shown that dietary intake of lutein is positively correlated with its optical density in retina (Hammond et al., 1996). Several studies have shown that higher level of macular pigmentation lowers the risk of eye diseases such as age-related macular degeneration (AMD) (Richer, 1999; Richer et al., 2004; Group, 2001). It has been also shown that increased lutein consumption reduces the risk of cataract (Moeller et al., 2008).

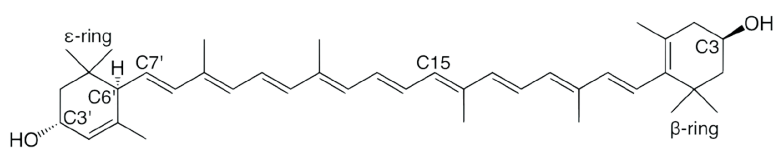

Figure 1. Chemical structure of lutein with indicated ionone rings and atoms that are used in analyses described below.
Lutein with a non-polar polyene chain and hydroxyl groups in 3 and $3^{\prime}$ positions (Fig. 1) should easily intercalate into a lipid bilayer. Linear dichroism measurements as well as monolayer compressing studies predict two orientations of lutein in lipid bilayers made of various phosphatidylcholines (PC) (Gruszecki, 2004): horizontal, where both hydroxyl groups interact with lipid headgroups in the same bilayer leaflet, and vertical, where each hydroxyl group interacts with lipid headgroups in the opposite bilayer leaflet. In each orientation, the lutein is able to perform a different biological function.

Structurally, lutein is very similar to zeaxanthin; its structure differs only in the position of the double bond in one of the rings. This difference might be responsible for the postulated different orientation of lutein than zeaxanthin in the bilayer (Gruszecki, 2004). In contrast to lutein, zeaxanthin is orientated only vertically in model membranes (Gruszecki, 2004).

In the present study, molecular modeling approach was used to determine orientations of lutein molecules in the PC bilayer as well as interactions stabilizing the orientations.

\section{METHODS}

In this study, we used classical molecular modeling with atomic resolution, mainly molecular dynamics (MD) simulation to study lutein intercalation and orientation in the hydrated 1-palmitoyl-2-oleoyl-phosphatidylcholine (POPC) bilayer. The initial structure of (3R, 3'R, 6'R) lutein was constructed using Avogadro program (Avogadro). The structure, with the Gasteiger-Marsili charges (Gasteiger \& Marsili, 1980), was optimized using Dreiding (Mayo et al., 1990) forcefield. Afterwards, the structure was fully optimized at B3LYP/6-31G(d) level of theory using Gaussian 09 program (Gaussian, 2010). For MD simulations, POPC and lutein molecules were parameterized using all-atom optimized potentials for liquid simulations (OPLS-AA) (Jorgensen et al., 1996), and for water, TIP3P parameters (Jorgensen et al., 1983) were used. A rotational profile for the $\mathrm{C}^{\prime}-\mathrm{C}^{\prime}$ dihedral angle in the lutein molecule (Fig. 1), based on the OPLS-AA parameters, was positively verified against that calculated at the B3LYP/6-31G(d) level of theory for 12 rotamers and that calculated by Landrum et al. (2010). In the POPC molecule, some of the original OPLS-AA parameters for $\mathrm{CH}, \mathrm{CH}_{2}$ and $\mathrm{CH}_{3}$ groups of the acyl chains

e-mail: marta.pasenkiewicz-gierula@uj.edu.pl

* Presented at the 16th International Symposium on Carotenoids, 17-22 July, 2011, Kraków, Poland

Abbreviations: MD, molecular dynamics; Oc, POPC carbonyl oxygen atoms; Op, POPC phosphate oxygen atoms; POPC, 1-palmitoyl-2-oleoyl-sn-glycero-3-phosphatidylcholine; RDF, radial distribution function. 
were modified to better reproduce the bilayer thermotropic phase (unpublished results). To this end, the point charges on $\mathrm{C}$ and $\mathrm{H}$ atoms were altered to match calculated dipole moments of $\mathrm{C}-\mathrm{H}$ bonds (Vereshchagin \& Vulfson, 1966) in these groups. The new point charges are: in $-\mathrm{CH}_{2}-0.24 \mathrm{e} \mathrm{C},+0.12 \mathrm{e} \mathrm{H}$; in $-\mathrm{CH}_{3}-0.48 \mathrm{e} \mathrm{C}$, $+0.16 \mathrm{e} \mathrm{H}$; and in $=\mathrm{CH}-0.23 \mathrm{e} \mathrm{C},+0.23 \mathrm{e} \mathrm{H}$. It is interesting to note that in case of $-\mathrm{CH}_{2}$ and $=\mathrm{CH}$ groups, new point charges are exactly twice as large as in the original OPLS-AA parameter set.

Six lutein molecules were added to the 200 -ns equilibrated bilayer system consisting of 200 POPC and 6000 water molecules (Plesnar et al., 2012). Lutein molecules were located on the bilayer surfaces, three on each side, on the water phase side (Fig. 2). Altogether, two systems with the same molecular composition and slightly differing initial positions of the lutein molecules, were constructed and optimized (system_1, and system_2). MD simulations of the two systems were carried out for 200 ns using Gromacs 4.5.4 package (Hess et al., 2008). LINCS algorithm (Hess et al., 1997) was used to preserve lengths of covalent bonds with hydrogen atoms, and the time step was set to 2 fs. Long-range electrostatic interactions were evaluated by means of the particle-mesh Ewald summation method with the $\beta$-spline interpolation order of 5 , and a direct sum tolerance of $10^{-6}$ (Essmann et al., 1995). For the real space, threedimensional periodic boundary conditions with the usual minimum image convention and a cutoff of $1 \mathrm{~nm}$ were used. The list of non-bonded pairs was updated every 5 steps. Simulations were carried out at a constant temperature of $310 \mathrm{~K}=37^{\circ} \mathrm{C}$, which is above the main phase transition temperature for a pure POPC bilayer $\left(-5^{\circ} \mathrm{C}\right.$, Seelig \& Waespe-Sarcevic, 1978), and a constant pressure of $1 \mathrm{~atm}$. Temperatures of the solute and solvent were controlled independently by the Nose-Hoover method (Hoover, 1985), pressure was controlled anisotropically by the Parrinello-Rahman method (Parrinello \& Rahman, 1981), both relaxation times were set at $0.6 \mathrm{ps}$.

\section{RESULTS}

\section{Location and orientation of lutein}

In order to check the readiness of the lutein molecules to intercalate into the POPC bilayer and to check their orientations during the simulations, the vertical position of the C15 carbon atom in each of the six lutein molecules as a function of time, was recorded (Fig. 3). Also, time profiles of $z$-coordinates of center-of-masses of the $\beta$-ring and the $\varepsilon$-ring of the lutein molecules that intercalated into the hydrophobic core of the bilayer, were recorded (Fig. 3).

In each system, one of the six lutein molecule had intercalated into the bilayer and that occurred within the first 2 ns of MD simulations. Both molecules penetrated the bilayer hydrophobic core from the $\beta$-ring-side. In system_1, the intercalated molecule placed itself horizontally at a depth of POPC carbonyl oxygen atoms and remained in such a position for the next 80 ns of $\mathrm{MD}$ simulation. After that time, it gradually switched to the vertical orientation, in which it remained until the end of the simulation. In system_2, the situation was opposite. The lutein molecule first penetrated one leaflet of the bilayer in a vertical orientation, and at about 70 . ns of the simulation, it reoriented to horizontal position and remained in that orientation until the end of the simulation. Lutein molecules that did not intercalate into the

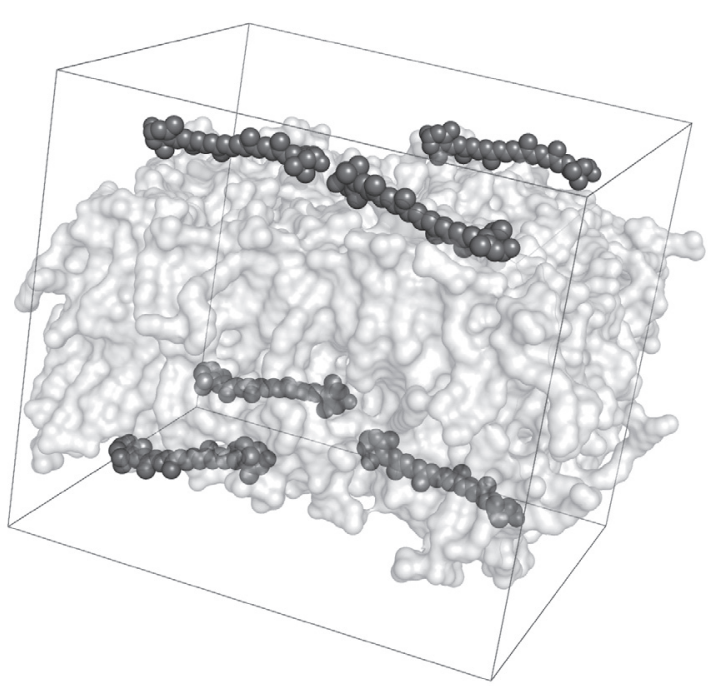

Figure 2. Initial location of six lutein molecules on the POPC bilayer upper and lower surfaces after energy minimization system_1.
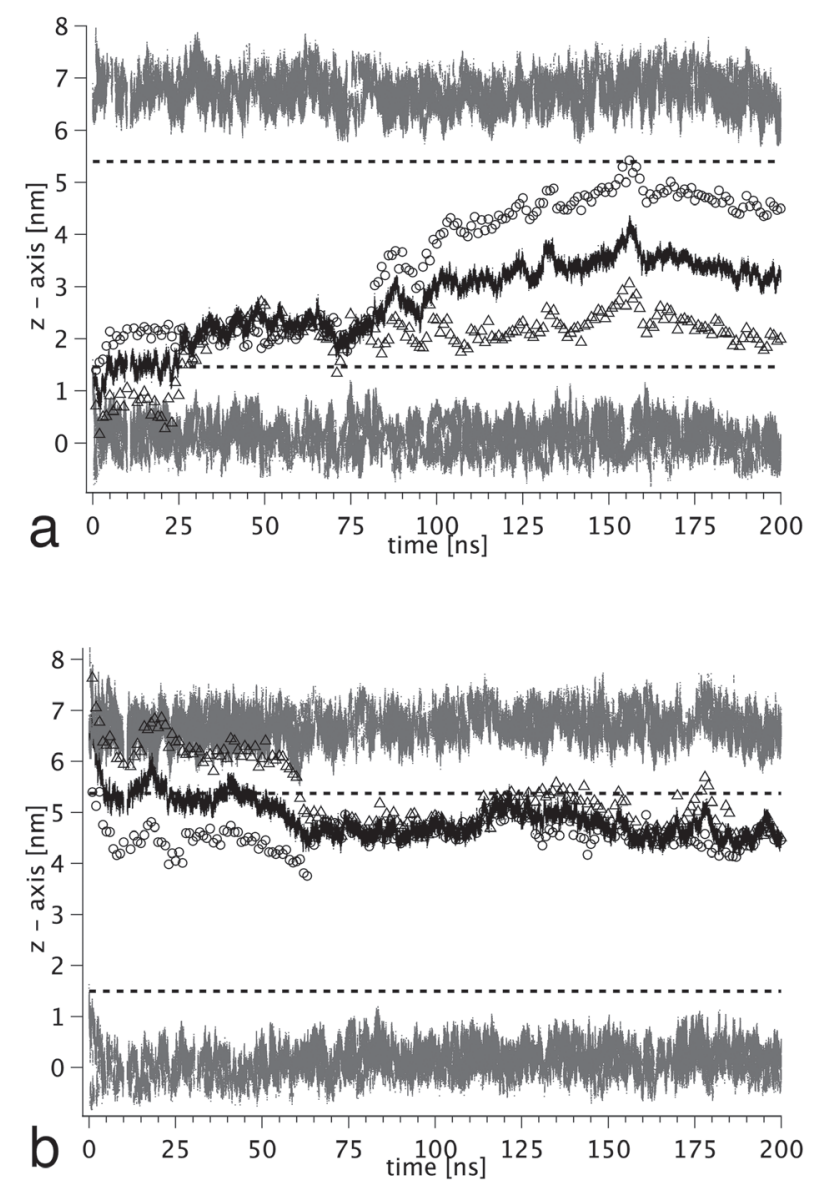

Figure 3. Time profiles of vertical locations (z-axis) of C15s (Fig. 1) of the lutein molecules remaining outside the bilayer (gray lines) and intercalated into the bilayer (black lines) as well as center-of-masses of the $\beta$ (open circles) and $\varepsilon$ (open triangles) rings of the intercalated lutein molecules. Two horizontal dashed lines indicate the average vertical location of the POPC $P$ atoms in each of the bilayer leaflets; (a) system_1, and (b) system_2. 

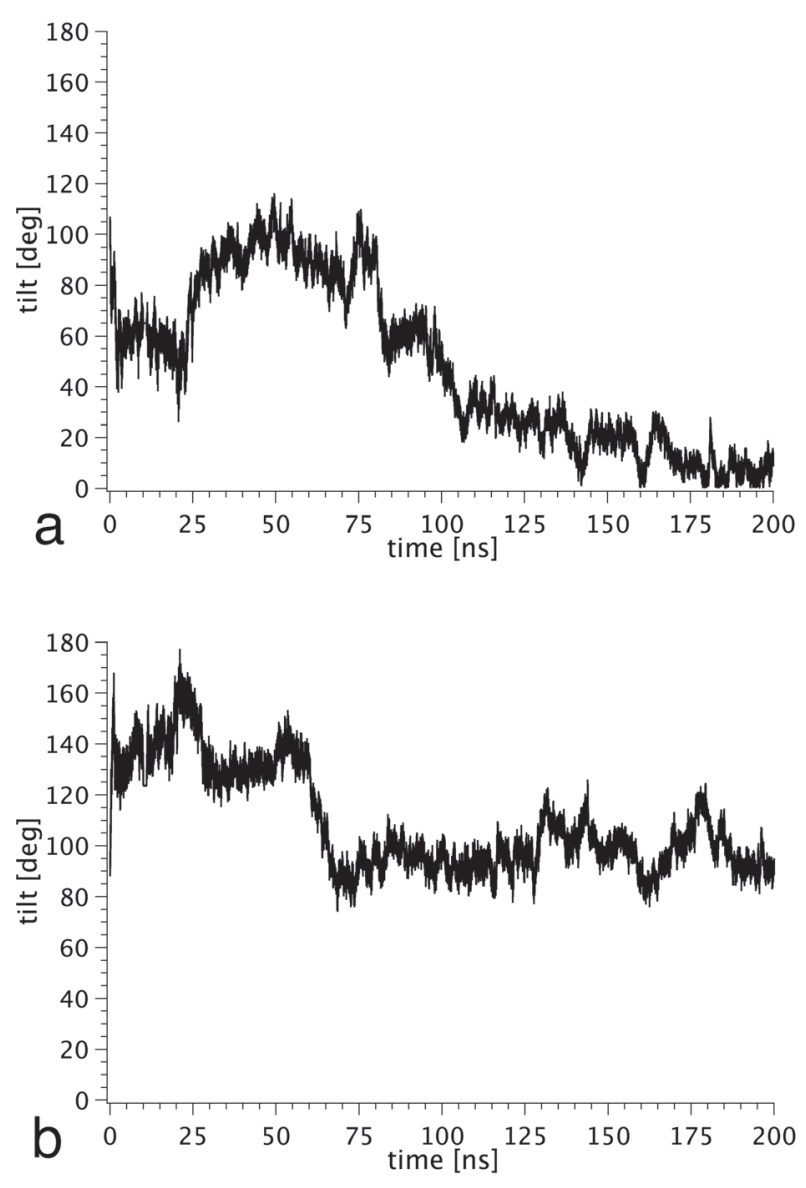

Figure 4. Time profiles of the lutein tilt angle (for definition, see text) in the bilayer, (a) system_1, and (b) system_2.

bilayer, aggregate in the aqueous phase and remained in such a form for the rest of MD simulations.

In order to obtain a more precise picture of the process of lutein reorientation in the bilayer, time evolution of tilt angles of both intercalated lutein molecules was recorded (Fig. 4). The lutein tilt angle is defined as the angle between the vector connecting the center-of-masses of both ionone rings and the bilayer normal.

In system_1, the lutein reorientation process was "smooth", which could be explained by the necessity of reorganization of the lipids in both bilayer leaflets to enable the lutein to locate across the bilayer. In system_2, lutein reorientation occurred only in one bilayer leaflet, permitting a dynamic, stepwise character of the change of the orientation.

\section{Specific lutein-POPC interactions}

In both systems, the lutein molecules intercalated into the bilayer changed their initial orientation at around $70-80$ ns of MD simulations and then kept on the new orientation for the remaining time of 120-130 ns. To check, what interactions stabilized these new, stable orientations of the lutein molecules in the bilayer, we inspected specific, i.e., involving polar groups, POPC-lutein interactions by calculating radial distribution functions (RDF) of lutein oxygen atoms of both $\beta$ and $\varepsilon$ rings relative the POPC carbonyl (Oc) and phosphate (Op) oxygen atoms, lutein-Oc and lutein-Op RDF, respectively (Fig. 5). The position of the first peak in RDFs in Fig. 5 $(\sim 0.27 \mathrm{~nm})$ indicates formation of hydrogen $\left(\mathrm{H}_{-}\right)$bonds between the lutein $\mathrm{OH}$ groups and Oc and Op atoms.

The lutein molecule in system_1 makes H-bonds with Oc atoms via $\mathrm{OH}$ groups both in 3 and $3^{\prime}$ positions, and with $\mathrm{Op}$ atoms via $\mathrm{OH}$ groups in the $3^{\prime}$ position ( $\varepsilon$-ring) (Fig. 5a). Almost vertical orientation of lutein during most of the simulation results in sharp peak in the lutein-Op RDF indicating exposure of the $\varepsilon$-rings to the phosphate groups region of the bilayer. In system_2, the horizontal orientation of the lutein molecule is stabilized mainly by H-bonding with Oc atoms and only slightly, by H-bonding with Op atoms (Fig. 5b).

\section{Discussion}

The aim of this work was to obtain information about preferred orientations of lutein in a PC bilayer as well as about interactions stabilizing those orientations, using molecular modeling methodology. MD simulations results indicate that both vertical and horizontal orientations of lutein are possible, which agrees with the experimental results of the Gruszecki's group (Sujak et al., 1999; Sujak et al., 2000). MD simulation is, nevertheless, confined to a relatively short time-scale — in this case to $200 \mathrm{~ns}$, which otherwise is considered up to the present standards. Moreover, only two of twelve lutein molecules intercalated into the bilayer. Thus, based on the present MD simulations, one can only say, that after the first reorientation in each of the simulation systems, which took place during first $70-80$ ns of MD simulation, the orientation of the lutein molecule is stable for over 120 ns. However, it is not possible to say, for how much longer, and whether both vertical and horizontal orientations are the preferred ones or one or both of them is transit, and in the latter case, what is time
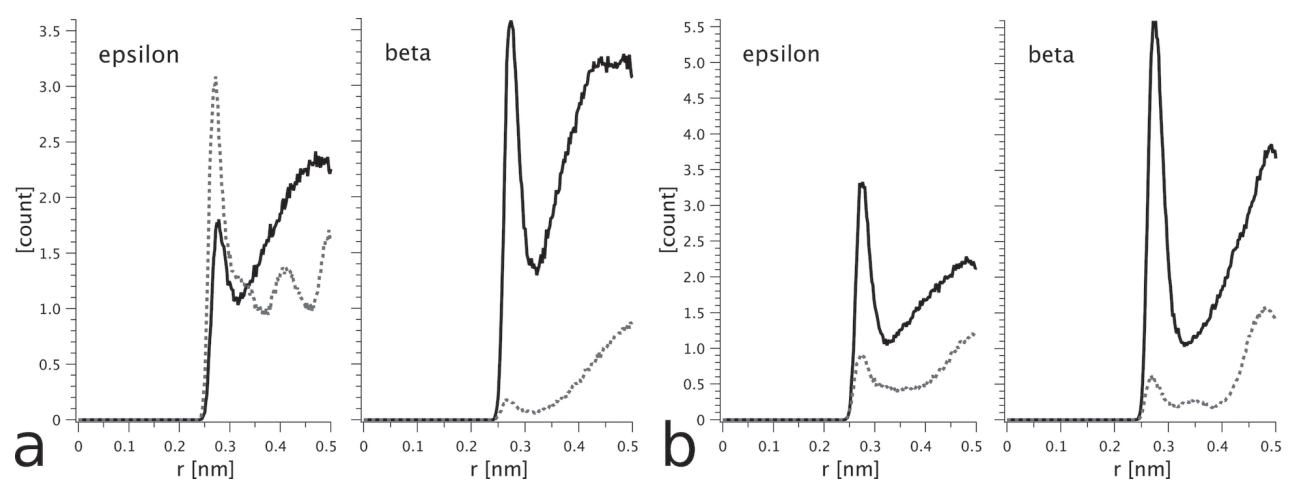

Figure 5. Lutein-POPC RDFs of the oxygen atoms in the lutein ionone rings and carbonyl (solid line) and phosphate (dotted line) oxygen atoms of POPC for (a) system_1, and (b) system_2. Please note that the ordinate scale differs in (a) and (b). 
scale of the following reorientations. It should be noted that the observed transition from horizontal to vertical orientation in system_1 was relatively slow most likely, because it involved reorientation of lipids in both bilayer leaflets. The vertical orientation of lutein is stabilized by lutein H-bonding with both Oc and Op atoms of POPC, whereas the horizontal orientation is stabilized mainly by lutein $\mathrm{H}$-bonding with only Oc atoms. In this study, we did not analyze nonpolar interactions between lutein and POPC in the bilayer. Further analyses are in progress.

\section{Acknowledgements}

Some calculations were performed on the cluster purchased under contract No. POIG.02.01.00-12-167/08, project MCB.

\section{REFERENCES}

Avogadro: an open-source molecular builder and visualization tool. Version 1.0.3. http:/ / avogadro.openmolecules.net/

Bernstein PS, Khachik F, Carvalho LS, Muir GJ, Zhao DY, Katz NB (2001) Identification and quantitation of carotenoids and their metabolites in the tissues of the human eye. Exp Eye Res 72: 215-223.

Essmann U, Perera L, Berkowitz ML, Darden T, Lee H, Pedersen LG (1995) A smooth particle mesh Ewald method. J Chem Phys 103: 8577-8593.

Gasteiger J, Marsili M (1980) Iterative partial equalization of orbital electronegativity - a rapid access to atomic charges. Tetrahedron 36: 3219-3228.

Gaussian 09, Revision B.01 Frisch MJ, Trucks GW, Schlegel HB, Scuseria GE, Robb MA, Cheeseman JR, Scalmani G, Barone V, Mennucci B, Petersson GA, Nakatsuji H, Caricato M, Li X, Hratchian HP, Izmaylov A,F Bloino J, Zheng G, Sonnenberg JL, Hada M, Ehara M, Toyota K, Fukuda R, Hasegawa J, Ishida M, Nakajima T, Honda Y, Kitao O, Nakai H, Vreven T, Montgomery Jr JA, Peralta JE, Ogliaro F, Bearpark M, Heyd JJ, Brothers E, Kudin KN, Staroverov VN, Keith T, Kobayashi R, Normand J, Raghavachari K, Rendell A, Burant JC, Iyengar SS, Tomasi J, Cossi M, Rega N, Millam NJ, Klene M, Knox JE, Cross JB, Bakken V, Adamo C, Jaramillo J, Gomperts R, Stratmann RE, Yazyev O, Austin AJ, Cammi R, Pomelli C, Ochterski JW, Martin RL, Morokuma K, Zakrzewski VG, Voth GA, Salvador P, Dannenberg JJ, Dapprich S, Daniels AD, Farkas Ö, Foresman JB, Ortiz JV, Cioslowski J, Fox DJ (2010) Gaussian, Inc., Wallingford CT.

Group A-REDS (2001) A randomized, placebo-controlled, clinical trial of high-dose supplementation with vitamins $\mathrm{c}$ and e, beta carotene, and zinc for age-related macular degeneration and vision loss: Areds report no. 8. Arch Ophthalmol 119: 1417-1436.

Gruszecki WI (2004) Carotenoid Orientation: Role in Membrane Stabilization. In Carotenoids in Health and Disease. Krinsky NI, Mayne ST, Sies H, eds, pp 151-162. Marcel Dekker Inc., New York.

Hammond BR, Curran-Celentano J, Judd S, Fuld K, Krinsky NI, Wooten BR, Snodderly DM (1996) Sex differences in macular pigment optical density: relation to plasma carotenoid concentrations and dietary patterns. Vision Res 36: 2001-2012.

Hammond BR, Wooten BR, Snodderly DM (1997) Individual variations in the spatial profile of human macular pigment. J Opt Soc Am A Opt Image Sci Vis 14: 1187-1196.
Hess B, Bekker H, Berendsen HJC, Fraaije JGEM (1997) LINCS: a linear constraint solver for molecular simulations. J Compt Chem 18: 1463-1472.

Hess B, Kutzner C, van der Spoel D, Lindahl E (2008) Gromacs 4: Algorithms for highly efficient, load-balanced, and scalable molecular simulation. J Chem Theor Comput 4: 435-447.

Hoover WG (1985) Canonical dynamics: Equilibrium phase-space distributions. Phys Rev A 31: 1695-1697.

Jorgensen WL, Chandrasekhar J, Madura JD, Impey RW, Klein ML (1983) Comparison of simple potential functions for simulating liquid water. I Chem Phys 79: 926-935.

Jorgensen WL, Maxwell DS, Tirado-Rives J (1996) Development and testing of the OPLS all-atom force field on conformational energetics and properties of organic liquids. J Am Chem Soc 118: 1122511236.

Khachik F, Bernstein PS, Garland DL (1997) Identification of lutein and zeaxanthin oxidation products in human and monkey retinas. Invest Ophthalmol Vis Sci 38: 1802-1811.

Landrum JT, Chatfield DC, Mebel AM, Alvarez-Calderon F, Fernandez MV (2010) The conformation of end-groups is one determinant of carotenoid topology suitable for high fidelity molecular recognition: a study of beta- and epsilon-end-groups. Arch Biochem Biophys 493: 169-74.

Mayo SL, Olafson BD, Goddard WA (1990) DREIDING: a generic force field for molecular simulations. J Phys Chem 94: 8897-8909.

Moeller SM, Voland R, Tinker L, Blodi BA, Klein ML, Gehrs KM, Johnson EJ, Snodderly DM, Wallace RB, Chappell RJ, Parekh N, Ritenbaugh C, Mares JA, CAREDS Study Group, Women's Health Initiative (2008) Associations between age-related nuclear cataract and lutein and zeaxanthin in the diet and serum in the carotenoids in the age-related eye disease study, an ancillary study of the women's health initiative. Arch Ophthalmol 126: 354-364.

Parrinello M, Rahman A (1981) Polymorphic transitions in single crystals: A new molecular dynamics method. J Appl Phys 52: 7182-7190.

Plesnar E, Subczynski WK, Pasenkiewicz-Gierula M (2012) Saturation with cholesterol increases vertical order and smoothes the surface of the phosphatidylcholine bilayer: A molecular simulation study. Biochim Biophys Acta - Biomemb 1818: 520-529.

Richer S (1999) Armd-pilot (case series) environmental intervention data. J Am Optom Assoc 70: 24-36.

Richer S, Stiles W, Statkute L, Pulido J, Frankowski J, Rudy D, Pei K, Tsipursky M, Nyland J (2004) Double-masked, placebo-controlled, randomized trial of lutein and antioxidant supplementation in the intervention of atrophic age-related macular degeneration: the veterans last study (lutein antioxidant supplementation trial). Optometry, 75: 216-230.

Seelig J, Waespe-Sarcevic N (1978) Molecular order in cis and trans unsaturated phospholipid bilayers. Biochemistry 17: 3310-3315.

Snodderly DM, Auran JD, Delori FC (1984) The macular pigment. II. Spatial distribution in primate retinas. Invest Ophthalmol Vis Sci 25: 674-685.

Sujak A, Gabrielska J, Grudziński W, Borc R, Mazurek P, Gruszecki WI (1999) Lutein and zeaxanthin as protectors of lipid membranes against oxidative damage: the structural aspects. Arch Biochem Biophys 371: 301-7.

Sujak A, Okulski W, Gruszecki WI (2000) Organisation of xanthophyll pigments lutein and zeaxanthin in lipid membranes formed with dipalmitoylphosphatidylcholine. Biochim Biophys Acta 1509: 255-63.

Vereshchagin AN, Vulfson SG (1966) Inductive interaction of weak dipoles in saturated hydrocarbons and their derivatives. Russ Chem Bul 16: 1186-1189. 